\title{
Assessment of the Capacity to Implement Competence-based Curriculum in Isiolo County Primary Schools, Kenya
}

\author{
Dr. Rukia Atikiya
}

School of Business and Technology Umma University, Kenya

\begin{abstract}
:
To address the shortfall of the outcome system of education (8-4-4) that is currently underway and to improve quality of education by making it more relevant to the need of the society, the Kenyan government embarked on yet another educational reform. This was the implementation of the competencebased curriculum which was rolled out in January, 2019 in pre- primary and lower primary levels of basic education. The purpose of this study was to assess the capacity to implement competence-basedcurriculum by Isiolo County Primary Schools. Descriptive research design was employed. The study sample comprised of 48 head teachers, 48 pre-school teachers, 13 parents with children in lower primary who were picked using snowballing, and 2 Ministry of education and County education officials who were picked using convenient sampling. Questionnaire and interview were the main tool used for data collection. The data was analyzed using descriptive statistics and thematic analysis for qualitative data. The findings of the study revealed that the teaching and learning materials are not adequate, the learning environment is not appropriate, inadequate teachers for competence-based curriculum delivery. Whilst most of the schools are connected to electricity, the schools had no computer labs, computers or libraries, which are key resource in the delivery of the competence-based curriculum. The study further revealed that the pre-school teachers are still ill-equipped to implement the new curriculum despite being trained and lacked computer skills. Majority of parents are also not sensitized on the content and their role in competence-based curriculum implementation hence not able to contribute positively. The study recommends provision of adequate learning and teaching materials, improvement of learning infrastructure, recruitment of additional teachers, enhancement of capacity of pre-school teachers through further training on $\mathrm{CBC}$ as well as computer skills, sensitization of parents as well as provision of additional finances to schools to ensure successful implementation of competence-based-curriculum
\end{abstract}

\section{Key Words: Competence Competence-based curriculum Implementation ill-equipped}

\section{Introduction}

Since independence in 1963, Kenyan educational system has undergone through fundamental reforms. Before independence, the education was stratified along racial line (African Education, European Education and Asian Education), (Ominde report, 1964). The realization of independence ushered in a new wave for education reform to address the main short fall of a system that was 'education along racial line' and come up with a single educational system for all. The first education commission was then formed (Ominde commission). The task of the Commission was to develop an education system that promotes national unity and instills in learners the desire to serve the country (Simiyu, 2001). Based on this, in 1964, the first education system (7-4-2-3) was implemented. Seven years of primary school, four years of lower secondary education (form 1-4), two years of upper secondary education, (Form 5 and 6) and at least three years of university education. The system did not however factor in the early childhood education. This system of education was later criticized for being too academic and therefore not suitable for direct employment. With the growing number of unemployed graduates, stakeholders exclaimed that the country needed another education system that would address the existing crisis of unemployment among university graduands. This made the country to commence yet another education reform which resulted in the introduction of 8-4-4 system in 1985 following the Mackay report of (1982). This system consists of (eight years in primary 
school, four years in secondary school and four years of University education). The introduction of this new system emanated from the assumption that it would equip learners with employable skills hence enabling the school dropout to be self-employed or seek for jobs in the informal sector. Despite being one of the major educational reforms experienced in Kenya since independence, the system was subject of discussion right at its commencement and was later faulted for being too broad, expensive and burdensome to learners and the parent (Amutabi, 2003). 8-4-4 system, like the previous system (7-2-3-3) did not also include the early childhood education. In the year 2017, based on educational expert report that declared the current education system (8-4-4) to be unfit for the $21^{\text {st }}$ century, the country moved to implement competence-based curriculum. The new curriculum framework (2-6-3-3-3) i.e. two years in lower primary, six years in upper primary, three years in lower secondary, three years in upper secondary and three years at the University was launched in 2017 and rolled out in January, 2019.

While competence-based education is new in Kenya the concept is not a new development globally. Competence-based education finds its roots in the European continent but has currently been appreciated by a number of African countries as well. These includes among others, South Africa, Senegal, Rwanda, Botswana and Tanzania. Whereas the move towards competence-based education is quickly gaining popularity due to its ability to stimulate learning and prepare learners properly for today's society (Westera, 2001), there still hardly exist any evidence of its effectiveness. Many of the countries that have adopted $\mathrm{CBC}$ have experienced myriad of challenges hence the need to pay keen attention to its implementation. Therefore, this study aims to evaluate the ability of schools in Isiolo County to adopt a competence-based curriculum and to identify the deficiencies that need to be resolved in order to effectively implement the newly commissioned competence-based curriculum in Kenya's primary schools.

\subsection{Statement of the Problem}

The introduction of competence-based curriculum was anticipated to address the shortfall of the 8-4-4 system that was faulted for being too broad, expensive as well as being too academic. This shift calls for a number of changes namely; teacher training, infrastructure improvement, provision of learning materials and institutional reorganization in terms of learning environment. However, since the implementation of the competence-based curriculum there exist no evidence of thorough assessment on the preparedness of county schools in the country to ascertain their ability to implement the competence-based curriculum apart from workshops conducted to train the teacher on the new curriculum. As much as the government commitment to ensure effective implementation of the new curriculum is not contested, there are still questions as to whether primary schools across the country are well prepared to be able to effectively implement the competence-based curriculum. It is against this backdrop that the current study seeks to assess the capacity to implement competence-based curriculum in Isiolo County schools in Kenya.

The study was guided by the following general and specific objectives;

\subsection{General objective of the study}

The general objective of the study was to assess the capacity to implement competence-based curriculum in Isiolo County primary schools.

\subsection{Specific Objectives}

The study was guided by the following specific objectives;

1. To establish adequacy of educational infrastructure to implement competence-based curriculum in Isiolo County primary schools.

2. To assess teacher preparedness to implement competence-based curriculum in Isiolo County primary schools.

3. To evaluate perception of parents on competence-based curriculum implementation in Isiolo County primary schools.

4. To find out the challenges experienced in implementing competence-based curriculum in Isiolo County Primary schools. 
This study is anchored on curriculum implementation theory by Gross (1971) and Vygotsky's social learning theory (Vygotsky, 1978) respectively. According to Gross, successful implementation of any educational program, requires among others teacher ability, support facilities and clarity of implementers. Whereas, Vygotsky on the other hand emphasizes that learning by children happens through social interaction and that learning extends beyond classroom to homes and parents take over to assist the learners. These theories were found to be relevant as they are about curriculum development and social learning mainly focusing on parental role in implementation of competence-based curriculum respectively which is the focus of the current study.

\subsection{Literature Review}

According to Asfani, Suswanto and Wibawa, 2016, adequate learning facilities and infrastructure positively promotes and influences learning among students and educators. However, a joint report by ILO/UNESCO (2009) revealed that most developing countries have a problem of overcrowded classrooms which undermine teacher competency in curriculum delivery of quality education. Osifila (2004) in his study on correlation between physical facilities and student academic performance established that there is significant relationship between adequate physical facility and teacher effectiveness in class and student academic outcomes. Ajayi (2009) in his study on the relationship between adequacy of instructional materials such as books, teaching and learning aids and teacher curriculum implementation in Nigerian secondary school found out that there is significant relationship between availability and effective use of teacher instructional materials and curriculum implementation in secondary schools. Adeleke (2007) study established that competence-based curriculum in Nigeria faces problems such as inadequate physical facilities, instructional materials, limited competent and qualified teachers, inadequate funding as well as lack of teacher motivation. Similar view is held by (Badugela, 2012) that students are guaranteed of hands on experience with adequate laboratories while libraries offer learners a wide range of reference materials. Mundia, (2017) posit that insutrcutional resources are channel of communication in classroom for purposes of experiencing learning and teaching while Delay (2010) avers that instructional materials should be made available through different tools such as books, videos, flipcharts among others.

On the other hand, teacher influence on implementation of new curriculum delivery cannot be under rated since the delivery of the curriculum purely depends on teacher preparedness. According to Howes (1997), curriculum implementation cannot be divorced from teacher training. A study by Hwande and Mpofu (2017) on preparedness of primary schools to implement new curriculum in Zimbabwe revealed that teacher development training received was not equal to the requirement of the new curriculum. In addition, there was no textbooks and internet despite the new curriculum requiring internet search among teachers. A study by Waweru (2018) on the influence of teacher preparedness on the implementation of competence-based education in primary schools established that teachers are not prepared in implementing the new curriculum. The study further highlighted that teachers needed support in infusing creativity and imagination, designing assessment rubric tailored towards discovering learner's ability to perform specific tasks. A report on teacher competence and preparedness by Kimosop (2019) also found that most of the county's pre-school teachers were not well prepared to adopt the program. Rop and Mumanyi (2019) conducted a report on teacher preparedness in lower primary schools in Bomet County, Kenya, to introduce a competency-based curriculum. The results showed that the teachers are ill-prepared to efficiently assess learner performance. Ondimu (2018) did a study on teacher preparedness for implementation of competence-based curriculum in private pre-schools in Dagoreti North Sub-county, Nairobi Kenya. The study revealed that the teachers lacked information, communication and technology (ICT) skills, there was inadequate instructional materials, higher teacher to student ratio as well as lack of parental support that hindered the smooth implementation of the curriculum.

Several studies have been undertaken on parental involvement and its effect on educational processes over the years (Berger, 2008; Davies, 1996; Epstein 2009) among others. Parental engagement in competencebased curriculum therefore, is also important as this is one of the requirements of the competence-based curriculum that requires parents to be co-educators to help teachers identify the children natural talents and abilities and work with the teachers to nurture them (KICD,2017). Similarly, parents are able to help teachers know the child's capabilities and characteristics (Ailincai et. al. 2016). 


\subsection{Methodology}

The study employed descriptive research design utilizing both quantitative and qualitative approaches. The target population for the study was 162 primary schools in Isiolo Town (94 public and 68 private), parents who had children in lower primary level where $\mathrm{CBC}$ is being implemented and county education representatives who were picked using snowballing and convenient sampling techniques respectively. Key informant Interviews were held with the selected parents and county education officers to get their perceptions on competence-based curriculum implementation while questionnaires were used to collect data from headteachers and pre-school teachers. Data collected was analyzed using descriptive statistics for quantitative data while for qualitative data, thematic analysis was used to organize the response into identified themes.

\subsection{Sample and Sampling Procedure}

The schools in Isiolo town both public and private were stratified as shown in Table 1. Thereafter, $30 \%$ of the schools were randomly sampled under each category. Purposive sampling was used to pick all the headteachers and at least one pre-school teacher. These categories of respondents were picked as they had capacity to provide relevant information based on the phenomenon under investigation (Marshall, 1996). This study therefore, utilized 96 participants from schools, 13 parents who had children in lower primary school where competence-based curriculum is underway identified using snowballing, as well as 2 county education identified through convenient sampling technique.

\section{Table 1: Sampling Procedure}

\begin{tabular}{|l|c|c|c|c|}
\hline Category & No. of Schools & Schools sampled & Headteachers & $\begin{array}{c}\text { Pre-school } \\
\text { Teachers }\end{array}$ \\
\hline Public & 94 & $0.3 \times 94=28$ & 28 & 28 \\
\hline Private & 68 & $0.3 \times 68=20$ & 20 & 20 \\
\hline Total & $\mathbf{1 6 2}$ & $\mathbf{4 8}$ & $\mathbf{4 8}$ & $\mathbf{4 8}$ \\
\hline
\end{tabular}

\subsection{Materials and Methods}

The level of preparedness of the schools was assessed using both qualitative and quantitative approaches, Interview were held with parents and selected County and Ministry of Education representatives. Quantitative data was also collected by use of questionnaires from school head teachers and pre-school teachers. Headteachers were asked a total of fifteen questions. Some of these questions included; whether the teachers have been trained, relevance of teaching and learning materials, whether parents have been sensitized on the competence-based curriculum, whether the school has connectivity to electricity, availability of computer lab, teacher competency in ICT as well as challenges among others. Pre-school teachers were also asked a total of fifteen questions. Apart from the demographic questions, the teachers were asked among others, whether they have been trained on competence-based curriculum, knowledge of content of the new curriculum, their competency in ICT, engagement with parents, appropriateness of teaching and learning materials as well as challenges they experience. The interview with parents majorly focused on their understanding of competence-based curriculum, whether they have been sensitized by the school, frequency of engagement by the school and challenges. Similarly interview with County and Ministry officials was intended to establish what has been done to ensure pre- school teachers are prepared to effectively deliver competence-based curriculum, adequacy of educational infrastructure within the county, what they are doing to ensure effective implementation of competence-based curriculum and challenges experienced to ensure effective implementation of the competence-based curriculum.

\subsection{Results and Discussion}

This section presents the findings of the study and the discussion. First the results will be presented and later followed by discussion of the results. The study sought to assess the capacity to implement competencebased curriculum in Isiolo County by investigating four thematic areas which include establishing the adequacy of educational infrastructures to deliver competence-based curriculum, assessing teacher preparedness on the delivery of competence-based curriculum, finding the perception of parents and county 
education stakeholders on competence-based curriculum implementation and making inventory of the challenges experienced in implementing competence based curriculum.

\subsubsection{Educational infrastructure and implementation of competence-based curriculum}

Responses were sought from headteachers with regards to educational infrastructure in their schools. These relates to appropriateness of teaching materials, appropriateness of teaching and learning environment, infrastructures available in their schools among others. The responses are as discussed under different subsections.

\subsubsection{Appropriateness of learning materials}

Figure 1 shows that majority of headteachers $(60.7 \%)$ are of the opinion that the learning materials were inappropriate for teaching and learning. This finding corroborates with that of Ajayi (2009) that revealed significant relationship between availability and effective use of instructional materials and curriculum implementation in secondary schools in Nigeria as well as that of Mundia (2017) which heighted that instructional resources are communication channels for learning and teaching to happen.

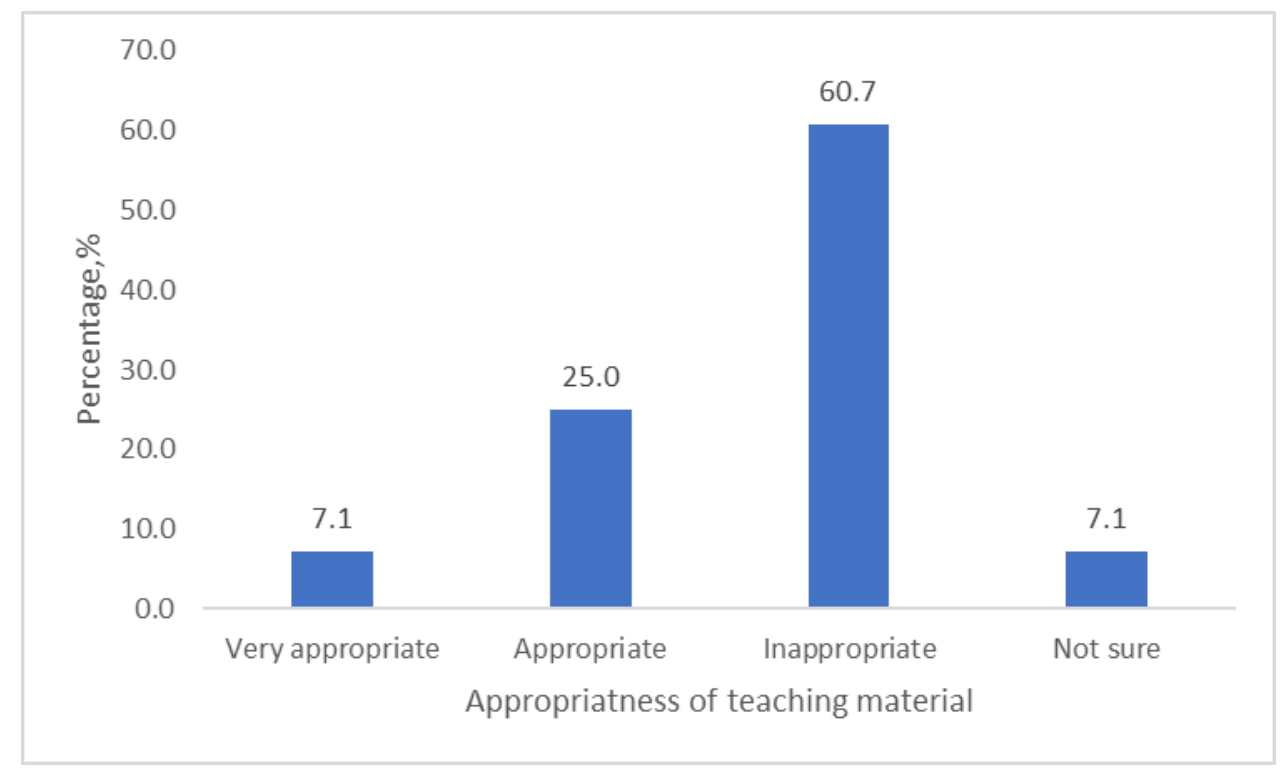

Figure 1: Appropriate of teaching materials

\subsubsection{Appropriateness of teaching and learning environment}

In terms of appropriateness of the teaching and learning environment, (93.5\%) of the head teachers indicated the environment was not appropriate or teaching and learning. The findings are as reflected in Table 2. This finding supports that of Osifila (2004) that established significant relationship between physical facility and teacher effectiveness as well as student academic outcomes. The study is also in line with that of Asfani et. al. (2016) that established that adequate learning facilities and infrastructure positively influence learning by students and educators.

Table 2: Appropriateness of teaching and learning environment

\begin{tabular}{|l|l|c|c|}
\hline \multicolumn{2}{|l|}{} & Frequency & Percent \\
\hline \multirow{2}{*}{} & Yes & 2 & 6.5 \\
\cline { 2 - 4 } & No & 29 & 93.5 \\
\hline
\end{tabular}

\subsubsection{Available infrastructure in the school}

On accessibility to a variety of infrastructure in schools, the study revealed that majority (71.4\%) of the schools had connectivity to electricity, whereas $28.6 \%$ had no electricity connectivity. Only $1 \%$ indicated to have access to a computer lab, while $96.4 \%$ had no access to computer lab. $28.6 \%$ of the schools had a library while $71.4 \%$ did not have access to a library. Majority of the respondents $(96.4 \%)$ said that the schools have no computers. $71.4 \%$ of the schools indicated to have a field while $28.6 \%$ had no access to a 
field. These findings are reflected in Table 3. Further interview with one of the County Education Official established that despite input from the County Government and development partners improving the school infrastructure through building of classrooms, most of the schools in the county still do not have basic infrastructure like latrines, kitchen, stores, fence and the classrooms available are very few compared to number of students. The finding supports the results of Badugela (2012) which established that students are guaranteed of hands-on experience with adequate laboratories while libraries provide wide range of reference materials.

Table 3: Presence of infrastructure in schools

\begin{tabular}{|l|c|c|}
\hline & Yes & No \\
\hline Access to & $\mathrm{n}(\%)$ & $\mathrm{n}(\%)$ \\
\hline Connectivity to electricity & $20(71.4)$ & $8(28.6)$ \\
\hline Computer lab & $1(3.6)$ & $27(96.4)$ \\
\hline Library & $8(28.6)$ & $20(71.4)$ \\
\hline Computers & $1(3.6)$ & $27(96.4)$ \\
\hline Field & $20(71.4)$ & $8(28.6)$ \\
\hline
\end{tabular}

\subsection{Teacher preparedness and implementation of competence-based curriculum}

Opinion were sought from pre-school teachers. The pre-school teachers were asked questions relating to number of trainings attended, knowledge on the content of competence-based curriculum, overall preparedness, computer literacy among others. The findings are as discussed under the different subheadings.

\subsubsection{Frequency of pre-school teacher training on CBC}

On average, $13 \%$ of the pre-school teachers had attended one training on CBC, $60.9 \%$ of the them had attended two trainings on CBC, whereas $26.1 \%$ had attended three trainings on CBC. Figure 2 shows the number of trainings attended. Interview with county education representative also confirmed that the preschool teachers have been trained on competence-based curriculum with support of national government and non-government support. The finding avers with Howes (1979) assertion that curriculum implementation cannot be divorced from any form of teacher training and that of Hwande and Mpofu (2017) which established that teacher development training received was not equal to the new curriculum need.

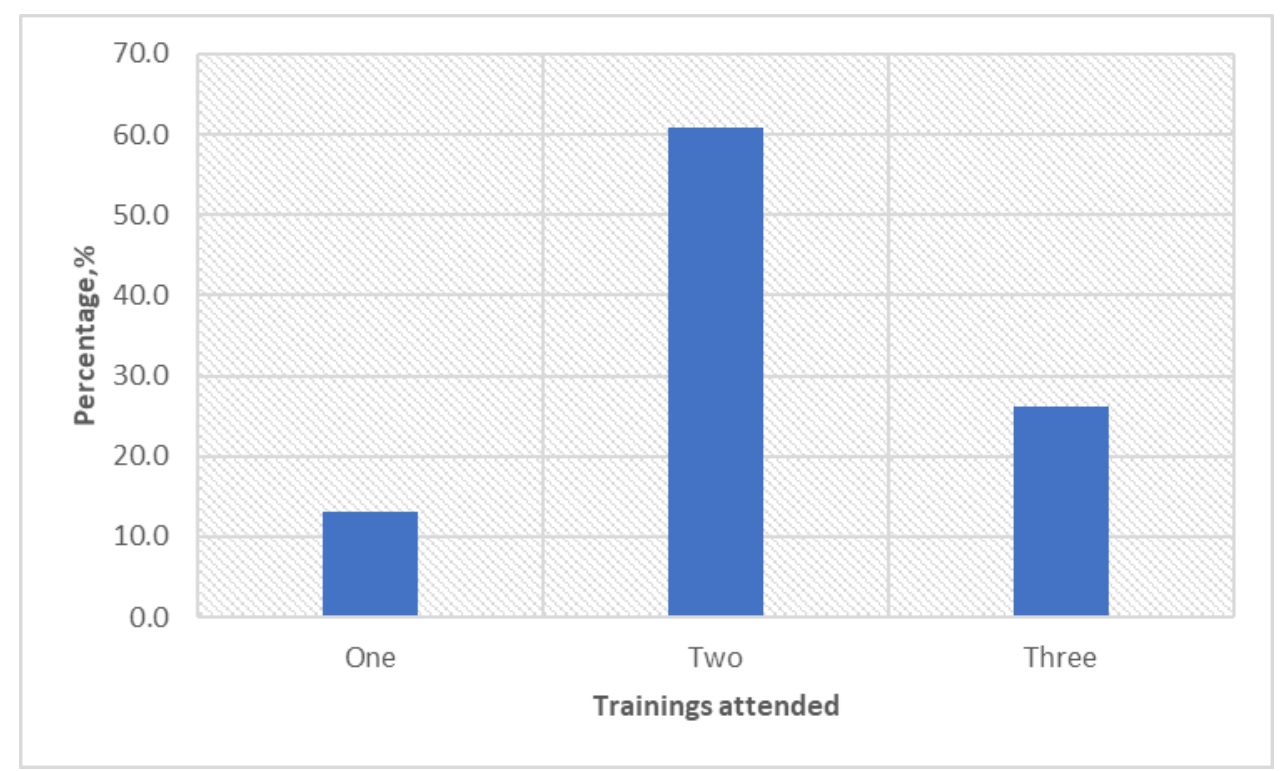

Figure 2: Number of trainings attended

\subsubsection{Knowledge of the content of $\mathrm{CBC}$ by pre-school teachers}


In terms of acquaintance with the contents of $\mathrm{CBC}$, one (3.2\%) preschool teacher indicated to be very conversant of the total preschool teachers. three $(9.7 \%)$ of the preschool teachers indicated to be conversant with CBC content. Twenty-one $(67.7 \%)$ teachers indicated to be moderately conversant whereas Five $(16.1 \%)$ of the preschool teachers said they were not conversant with the content of the competence-based curriculum. Table 4 shows these findings.

Table 4: Conversant of the content of CBC by pre-school teachers

\begin{tabular}{|l|l|c|c|}
\hline \multicolumn{2}{|l|}{} & Frequency & Percent \\
\hline \multirow{2}{*}{} & Very conversant & 1 & 3.2 \\
\cline { 2 - 4 } & Conversant & 3 & 9.7 \\
\cline { 2 - 4 } & Moderately conversant & 21 & 67.7 \\
\cline { 2 - 4 } & Not conversant & 5 & 16.1 \\
\hline
\end{tabular}

\subsubsection{Overall Teacher Preparedness}

A general view on whether teachers are well equipped showed that only $21.4 \%$ of pre-school teachers are well equipped, while $78.6 \%$ is of the opinion that teachers are not well equipped. These findings are expressed in Figure 2. An interview with the representative of county education also showed that teachers are not completely prepared to introduce the competence-based curriculum. Several studies support this finding (Waweru 2018; Rop \& Momanyi 2019; Kimosop, 2019).

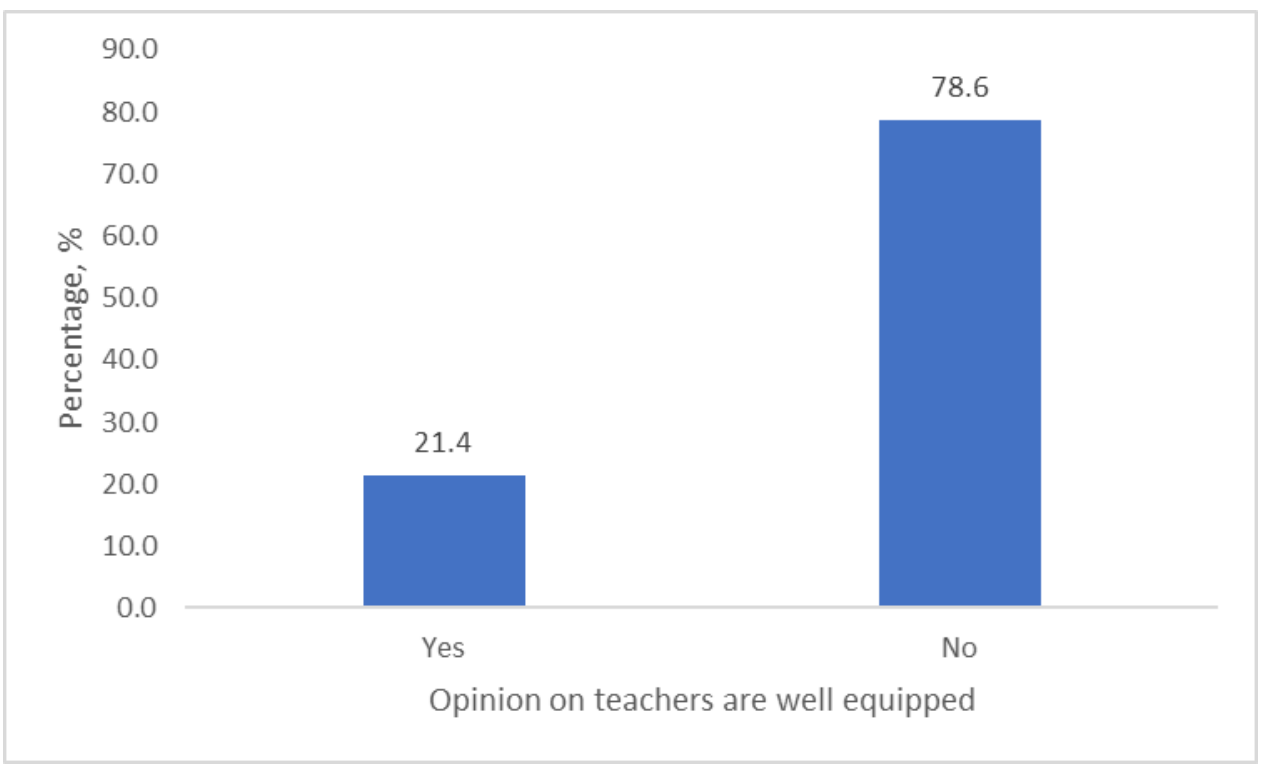

Figure 2: Overall teacher preparedness

\subsubsection{Computer Literacy}

Table 5 shows that response to the question on competency in computer use. (17.9\%) of the 28 teachers interviewed indicated that they were computer literate while $(82.1 \%)$ indicated that they were not computer literate. The finding corroborates with that of Ondimu (2018), that found out that lack of ICT competency among teachers hinders smooth implementation of competence-based curriculum.

Table 5: Computer literacy of teachers

\begin{tabular}{|l|l|c|c|}
\hline \multicolumn{2}{|l|}{} & Frequency & Percent \\
\hline & Yes & 5 & 17.9 \\
\cline { 2 - 4 } & No & 23 & 82.1 \\
\hline
\end{tabular}

\subsubsection{Usage of Computer in class}

Similarly, of the 31 of the pre-school teachers interviewed on whether they use computer to teach or not, only $5(16.1 \%)$ indicated to be using computer to teach while $26(83.9 \%)$ indicated that they do not use 
computer to teach. This is largely attributed to the incompetency in use of computers as reflected in Table 5. This result is reflected in Table 6 .

Table 6: Use of computers to teach

\begin{tabular}{|c|c|c|}
\hline & Frequency & Percent \\
\hline Yes & 5 & 16.1 \\
\hline $\mathrm{No}$ & 26 & 83.9 \\
\hline
\end{tabular}

\subsection{Perception of parents on competence-based curriculum implementation}

The study sought to investigate the perception of parents on CBC implementation. The parents were asked questions on whether they were oriented on competence-based curriculum and whether they are conversant with competence-based curriculum. Majority of the parents stated that they are conversant and that they were sensitized on competence-based curriculum. However, a faction of the parents claimed not to be conversant and not sensitized on the content of CBC. This finding corroborates with that of Ailincai, et. al. 2016 which established that parents are able to help teachers know the child's capabilities and characteristics and be co-educators to help teachers identify the child's natural talents and abilities and work with teaches to nurture them (KICD, 2017). In order to play their role in the implementation of the competence-based curriculum, it is therefore necessary for parents to be sensitized in order to be aware of the competencebased curriculum.

\subsection{Challenges experienced in implementing competence-based curriculum}

Various groups of participants sought a view on the difficulties faced in successfully implementing the competence-based program. The answers in various subsections are as categorized.

\subsubsection{Challenges experienced by Headteachers}

The headteachers expressed the opinion that successful implementation of the competence-based curriculum is hindered by; Inadequate finance to support the CBC delivery, inadequate teaching staff to ensure that $\mathrm{CBC}$ is delivered, inadequate teaching and learning materials for the teachers and pupils, lack of enough infrastructure to accommodate the pupils, parents not supportive of the new CBC as well as Education officials not being supportive.

\subsubsection{Challenges experienced by Pre-school teachers}

The pre-school teachers highlighted that the curriculum is too bulky, they have inadequate skills to deliver $\mathrm{CBC}$, inadequate teaching and learning materials since $\mathrm{CBC}$ involves practical aspects, inadequate computer skills to assist the pupils, difficulty coping with the new curriculum as well as unfriendly learning environment which hinders effective implementation of the competence-based curriculum.

\subsubsection{Challenges experienced by Parents}

The parents lamented that they are not sensitized on CBC so it is hard to track the progress of their children and understand their role in the implementation process. Lack of computer skills among parents also hinders their ability to assist their children do their homework. Further implementation of CBC has come with additional financial expenses since the children are always asked to bring learning materials needed for different content delivery.

\subsubsection{Challenges highlighted by Cunty Education Officers}

The education officials interviewed stated that key challenge affecting proper implementation of CBC is insufficient finances to procure necessary learning and teaching materials and human resource especially the teachers. Similarly, majority of schools in the county lack necessary infrastructure to implement CBC successfully.

\section{Conclusions and Recommendations}

This research revealed a number of significant findings on the extent of preparedness to adopt the program based on competence. In conclusion, in the county schools had insufficient learning and teaching, the 
learning environment in the competence-based set-up is not ideal for teaching and learning. Similarly, while most schools lacked access to electricity, basic facilities such as computers, computer laboratories and libraries were missing, which are instrumental in delivering the competence-based curriculum. The teachers, despite being trained are still ill-equipped to implement the competence-based curriculum. The teachers also lacked computer skills hence the competency to use computers to teach or impact literacy skills as required by the competence-based curriculum. Finally, parents expressed opinion that they were not oriented on the new curriculum and therefore not able to participate as key stakeholder in the implementation of the competence-based curriculum. They also felt that the curriculum is burdening them financially as they are frequently expected to provide learning aids to children.

Based on the findings of the study, the researcher recommends as follows;

\section{Implication of the study for Ministry of Education}

To ensure successful implementation of competence-based curriculum, the Ministry of Education should evaluate the competence-based curriculum training the teachers have been exposed to in order to assess its effectiveness since despite being trained, most of the teachers still felt they are ill-prepared to implement the curriculum. Capacity building for teachers in computer skills is also of paramount importance for them to effectively impart literacy skills to the learners. The Ministry should also improve increase financial disbursement to the schools for them to be able to acquire necessary learning and teaching materials necessary for the delivery of the competence-based curriculum. Moreover, the Ministry should also undertake monitor the implementation of the competence-based curriculum on quarterly basis to establish the gains and gaps in order to put in place necessary corrective measures in place to successfully implement the new curriculum.

\section{Implication of the study for the Headteachers}

The parent's role in competence-based curriculum is crucial for successful implementation of the competence-based curriculum, the headteachers should therefore, plan to engage the parents on termly basis in order to sensitize them on the new curriculum and their role in ensuring successful implementation of the competence-based curriculum.

\section{Implication of the study for the Pre-school teachers}

Being the primary implementers of the competence-based curriculum, the pre-school teachers need to be innovative and work with locally available resources in their bid to making the learning more practical and the learning environment more appealing to the learners. The teachers should also clarify the tasks that requires parental support so that the learners are able to submit their homework with ease. The teachers should also seek alternative means of improving their competency levels in computer skills to be able to impart the digital literacy skills to the learners effectively.

\section{Implication of the study for the Parents}

Parental involvement is key to the success of the learners. It is therefore, important that the parents work closely with the schools to be able to contribute to the successful implementation of the competence-based curriculum and contribute to academic success of their children though provision of necessary learning aids and feedback on learner abilities for the teachers to be able to help nurture them.

\section{Implication for the Teachers Service Commission}

Most of the public schools in the County, are struggling with large number of students and addressing each learner need is a challenge. Teachers Service Commission should therefore improve the staffing in public schools to ensure effective implementation of competence-based curriculum.

\section{Implication for the County and Development Partners}

Most of the schools in the region are struggling with infrastructural challenges. The County Government and development partners should work together to improve the existing infrastructures e.g. classrooms, latrines, kitchen, fencing and provide learning facilities such as laboratories and computers as well as capacity 
building for teachers so as to positively contribute to the successful implementation of the competence-based curriculum. Similarly, consideration should be given to provision of feeding program in public schools as most of the children in the county are from humble background. This will help keep the children in school as well as motivate them to learn.

\section{Theoretical Contribution}

The empirical results of this study help to explain how the proper implementation of the competence-based curriculum is improved by educational infrastructure, availability of learning and teaching resources, teacher preparedness and parental participation. The study established that adequate educational infrastructure, learning and teaching materials included, teacher preparedness and parental participation and awareness of their role positively influence successful implementation of competence-based curriculum.

\section{Limitations and suggestions for further research}

The current study utilized smaller sample and focused on only one of the Arid and Semi-Arid Land (ASAL) County. Further research should be undertaken utilizing larger sample and across other ASAL Counties to assess the level of preparedness to implement competence-based curriculum.

\section{Conflicts of Interest}

The author declares no conflict of interest.

\section{Funding Statement}

This research was supported by Umma University, Kenya through a grant awarded to Dr. Rukia Atikiya. I would like to express my gratitude for the support.

\section{Acknowledgments}

I wish to thank all parents, headteachers, Ministry of education officials at county level and pre-school teachers for their participation and contributions to this study.

\section{References}

[1] Adeleke, M. H. (2006). An appraisal of curriculum implementation in Nigeria, Lagos: Macus Publication.

[2] Ailincai, R., Gabillon, Z., Vernaudon, J., Paia, M. \& Ali, M. (2016). School and family involvement in educational practice in French Polynesia. International Conference on Academic Forum 1999 215: hal 0139810.

[3] Ajayi, S. N. (2009). Evaluation of Nigeria's Educational Goals, Lagos: Memphis Publishers.

[4] Ajibola, M.A. (2018). Innovations and curriculum implementation for basic education in Nigeria: Policy priorities and challenges of practices and implementation. Research Journal of International Studies. Issue 8 pg 51-58.

[5] Amutabi, M.N. (2003). The 8-4-4 system of education. International Journal of Educational Development. 23(3) pp. 177-144.

[6] Cheptoo, R. (2009). The "Africanized" competence-based curriculum: The Twenty-First Century Strides. International Journal of Education. Vol.7(4) pp 46-51.

[7] Hawes, M. (1979). Curriculum and reality in African Primary Schools: Longman Press.

[8] Hwande, E., \& Mpofu, J. (2017). The preparedness of Primary Schools to implement the Grade 3 New curriculum in Zimbabwe: Case study of Bulawayo Metropolitan Primary Schools.

[9] Joint ILO/UNESCO repot (2009). Committee of Expert on the Application of the Recommendations Concerning Teaching Personnel (CEART) report of the Tenth Session held in Paris, on $28^{\text {th }}$ September $-2^{\text {nd }}$ October 2009.

[10] Gross, N. (1971). Implementing Organizational Change. A sociological analysis of planned educational changes. New York: Basic Book Ink. 
[11] Kenya Institute of Curriculum Development (KICD, 2017). Facilitators training manual for early years education curriculum. Nairobi: Government Printer.

[12] Kimosop, H. (2019). Teacher preparedness in the implementation of Early Childhood Education Development Curriculum in Kenya: A case of Baringo North Sub-County, Kenya. IOSR. Journal of Humanities and Social Sciences (IOSR-JHSS). Vol.24 (2) pp. 44-50.

[13] Mackay, C. (1981). Second secondary: Report of presidential working panel. Nairobi: Government Printer.

[14] Ominde, S.H. (1964). Kenya Education Commission Report. Republic of Kenya. Nairobi: Government Printer.

[15] Ondimu, S.M. (2015). Teacher preparedness for implementation of competence-based curriculum in private pre-schools in Dagoreti North Sub-County, Nairobi County, Kenya. (Unpublished Master's Thesis). University of Nairobi, Kenya.

[16] Osifila, G.I. (2004). Provision and management of Physical plants as correlates of academic performance in Lagos State Public Secondary Schools. (Unpublished Master's Dissertation).

[17] Rop, P.K. \& Momanyi, J.M. (2019). Teacher preparedness for the implementation of competencebased curriculum in Kenya: A survey of Early Grade Primary School Teachers' in Bomet East SubCounty. The Cradle of Knowledge: African Journal of Educational and Social Science Research. Vol.7(1), pp. 10-15.

[18] Simiyu, J.W. (2001). Factors which influence the teaching of technical and vocational subjects in primary schools in Uasin Gishu, district, Eldoret: Unpublished Master's Dissertation. Moi University, Kenya.

[19] Vygotky, L.S. (1978). Mind in Society. The development of higher psychological processes. Cambridge, M. A: Harvard University Press.

[20] Waweru, W. J. (2018). Influence of Teacher Preparedness on the Implementation of Competencebased curriculum in public primary schools in Nyandarua North Sub-County, Kenya.

[21] Westera, W. (2001). Competences in Education: A confusion of Tongues. Journal of Curriculum Studies. Vol. 33(1). Pp 75-88. 